\title{
A cross sectional study to determine polycystic ovarian disease among students of a tertiary care teaching hospital
}

\author{
Raja Sekhar Jalemu' ${ }^{1}$, Kasthuribai Sabbe ${ }^{2 *}$, Grishma Jalemu ${ }^{3}$
}

\begin{abstract}
${ }^{1}$ Department of Obstetrics and Gynecology, GVP Medical College, Visakhapatnam, Andhra Pradesh, India ${ }^{2}$ Department of Obstetrics and Gynecology, Krishna Hospital Visakhapatnam, Andhra Pradesh, India

${ }^{3}$ Department of Obstetrics and Gynecology, Xavier School of Medicine Aruba, West Indies
\end{abstract}

Received: 09 June 2019

Revised: 31 July 2019

Accepted: 05 August 2019

\section{*Correspondence:}

Dr. Kasthuribai Sabbe,

E-mail: kasbi1961@gmail.com

Copyright: ( ) the author(s), publisher and licensee Medip Academy. This is an open-access article distributed under the terms of the Creative Commons Attribution Non-Commercial License, which permits unrestricted non-commercial use, distribution, and reproduction in any medium, provided the original work is properly cited.

\section{ABSTRACT}

Background: India now has highest number of patients with type 2 diabetes mellitus globally and speedy rise of the incidence of obesity in children is the major reason for increasing insulin resistance, the metabolic syndrome, dyslipidemia and polycystic ovarian syndrome. But proportion for PCOD is unknown in community. Objective of this study was to estimate the prevalence of PCOD among students in Tertiary care teaching hospital.

Methods: A cross sectional study was conducted among students of aged 16-24 years in a teaching hospital in Kerala. Sample sizes of 256 students were randomly selected from various batches of medical and paramedical courses. Occurrence of hyper androgenic features and menstrual irregularities were evaluated, and they were physically examined. The diagnosis of PCOS was made based on Rotterdam's criteria. Epi-info 7 was used for analysis.

Results: Seventy-five students $(30 \%)$ met the criteria to be diagnosed as polycystic ovarian syndrome. Twenty students $(10 \%)$ had a history of thyroid dysfunction. The other clinical features of hyperandrogenism were like acne $(25 \%)$, oily skin $(13.5 \%)$, and increased hair growth (7\%), male pattern thinning of hair $(9.75 \%)$.

Conclusions: PCOD can be assumed of as a forerunner syndrome that, if screened for, can help in early identification of risk of highly morbid conditions, in adolescent girls.

Keywords: Acne, Adolescent, Hyper androgens, Menstrual irregularities, Metabolic syndrome, PCOD, Risk factors

\section{INTRODUCTION}

Polycystic ovarian syndrome (PCOS) is one of the most communal endocrine disorders in women. The prevalence of polycystic ovarian syndrome ranges from $2.2 \%$ to $26 \%$ among the endocrine disorders. ${ }^{1-3}$ There are many interrelating factors which result in clinical and/or biochemical hyperandrogenism. The symptoms of PCOS appear slowly and these features are equivalent with the changes of normal pubertal development. So, these features may not be recognised in an early stage and leads for the failure to identify the disorder in young girls. Women with PCOS are at risk of obstructive sleep apnea, infertility, dysfunctional uterine bleeding, metabolic syndrome, type 2 diabetes, cardiovascular disease, depression. $^{4-7}$ So diagnosing PCOS at an early stage will help prevent these complications of maternal and child health which appears to cover two of the eight objectives of millennium development goals (MDG). ${ }^{8}$ Preventing measures like exercises, healthy diet, practicing meditation, calming exercise that reduce stress levels etc. play an important role in reducing the complications of 
PCOS. There is a rapid rise in the incidence of obesity in children which results in metabolic syndrome, dyslipidemia, insulin resistance and polycystic ovarian syndrome. The prevalence in Asian countries appears to be lower, with a reported prevalence of $2.4 \%$ in China 1 and $6.3 \%$ in Sri Lanka (Rotterdam criteria). ${ }^{9}$ Prevalence was found to be $6.8 \%$ in north Indian women. ${ }^{10}$ In view of the above cited causes and the fact that prevalence of this syndrome in our community remains unknown, we attempted to find its prevalence in medical, dental, nursing and paramedical female students, aged between 16-24 years, in a teaching hospital.

\section{METHODS}

Study design: Cross sectional study.

Study settings: Tertiary care teaching hospital of south India.

Study population: Students of aged 16-24 years were randomly selected from various batches and branches of medical and paramedical courses.

Ethical consideration: The Institutional Ethics Committee approval was obtained prior to the study.

Sample size: Based on the expected prevalence of $20 \% 10$ and confidence level $95 \%$, the sample size for this project was calculated to be 256 . Using the formula:

\section{PG/L2}

Where, P- prevalence of PCOD

$\mathrm{Q}=1-\mathrm{P}$

L- Absolute error at $95 \%$ confidence Interval.

Sampling technique: Simple random sampling.

\section{Inclusion criteria}

- The Female students doing course in the college and who were willing to go for an ultrasound examination were included in the study.

\section{Exclusion criteria}

- Students who didn't go for ultrasound and didn't give consent were excluded.

Although they were students of one college of a single area, they represented a larger geographical area because they were from urban, semi-urban and rural areas around the district. The study subjects were then distributed questionnaires which included questions pertaining to the presence of hyper androgenic features and menstrual irregularities (amenorrhoea/ oligomenorrhoea). The diagnosis of PCOS was made based on Rotterdam's criteria. The Rotterdam guidelines (2003) tell that the patient should have two of three criteria: oligo-or chronic anovulation, clinical and/or biochemical signs of hyperandrogenism, polycystic ovaries. Exclusion of other etiologies of androgen excess and anovulatory infertility is necessary. The ultrasound criteria defines the polycystic ovary as containing 12 or more follicles measuring 2-9mm and/or an increased ovarian volume of $>10 \mathrm{~cm}^{3} .{ }^{11}$ Menstrual disturbances in PCOS generally present in the form of oligo-amenorrhea (fewer than eight episodes of menstrual bleeding per year or menses that occur at intervals greater than 35 days). ${ }^{12}$

\section{Statistical analysis}

Collected data were consolidated into Microsoft excel sheet and then transferred into Epi-info 7 software for analysis. Data expressed in the form of proportion and percentages.

\section{RESULTS}

As per Table 1, the demographic profile and the average age of onset of menstruation among the students are depicted seventy-five students $(30 \%)$ met the criteria to be diagnosed as polycystic ovarian syndrome. The average BMI of those with PCOS is slightly higher (2.67) than those without it.

Table 1: Demographic details of the study participants.

\begin{tabular}{|lll|}
\hline Parameters & $\begin{array}{l}\text { With } \\
\text { PCOD }\end{array}$ & $\begin{array}{l}\text { Without } \\
\text { PCOI }\end{array}$ \\
\hline Number of students & $75(30 \%)$ & $171(70 \%)$ \\
\hline Age & $19.91 \pm 1.70$ & $19.32 \pm 1.04$ \\
\hline BMI & $22.79 \pm 4.89$ & $22.08 \pm 2.12$ \\
\hline $\begin{array}{l}\text { Average age of onset of } \\
\text { menstruation }\end{array}$ & $12.51 \pm 0.90$ & $13.03 \pm 0.38$ \\
\hline \begin{tabular}{l} 
Data are expressed as Mean \pm SD. \\
\hline
\end{tabular}
\end{tabular}

Table 2: Participants meeting the Rotterdam criteria.

\begin{tabular}{|ll|}
\hline Clinical features & $\begin{array}{l}\text { Proportion } \\
\text { of students }\end{array}$ \\
\hline Irregular periods & $26.86 \%$ \\
\hline $\begin{array}{ll}\text { Cyst or increased stroma in ovaries } \\
\text { Hirsutism }\end{array}$ & $32.14 \%$ \\
\hline $\begin{array}{l}\text { Both menstrual irregularity and cyst in } \\
\text { ovaries }\end{array}$ & $24.89 \%$ \\
\hline Both cyst in ovaries and hirsutism & $13.14 \%$ \\
\hline $\begin{array}{l}\text { Both menstrual irregularity and } \\
\text { hirsutism }\end{array}$ & $9.85 \%$ \\
\hline $\begin{array}{l}\text { Menstrual irregularity, cyst in ovaries } \\
\text { and hirsutism }\end{array}$ & $7.5 \%$ \\
\hline
\end{tabular}

As per Table 2 total number of students previously diagnosed with PCOS was $10.16 \%$. The percent of students having only menstrual irregularity with cyst $(22.47 \%)$ which is higher than those having only the other two combinations showing that a student with 
menstrual irregularity is more likely to have a cyst and vice versa. Twenty students $(10 \%)$ had a history of thyroid dysfunction. The clinical features of hyperandrogenism among those who had PCOS were like oily skin $(13.5 \%)$, acne $(25 \%)$, and increased hair growth $(7 \%)$, male pattern thinning of hair $(9.75 \%)$. The other hyperandrogenic features were not considered in the diagnosis of PCOS as there is no standardized method that uses these features to satisfy the Rotterdam criteria of clinical hyperandrogenism. None of the students gave a self or family history of late onset congenital adrenal hyperplasia or galactorrhoea.

\section{DISCUSSION}

PCOS is one of the most shared endocrine disorders among women but the diagnosis, management and the complications have not been consistent. Hyperandrogenism and menstrual irregularity are the most predominant symptoms of PCOS patients, but these symptoms are not absolute necessary for diagnosis of PCOS. Similarly, the ultrasonography indication of polycystic ovaries as a diagnostic marker doesn't validate much. In the present study the demographic profile and the average age of onset of menstruation among the students are depicted seventy-five students (30\%) met the criteria to be diagnosed as polycystic ovarian syndrome. The average BMI of those with PCOS is slightly higher (2.67) than those without it. The percent prevalence of PCOS was $30 \%$ which is comparable to some other studies done..$^{2,12,13}$ The increased prevalence of PCOS among young aged females may be due to unhealthy dietary habit like junk foods, lack of exercises, sedentary lifestyles. The childhood obesity can lead to insulin resistance and metabolic syndrome in later part of the life. Stress is one of the major factors for all types' diseases now a day. ${ }^{14}$ The changed lifestyle disorder can cause increased stress among the adolescents. So, the students should be stimulated to follow stress relieving techniques like yoga, meditations and to adapt the lifestyles. In the present study total number of students previously diagnosed with PCOS was $10.16 \%$. The percent of students having only menstrual irregularity with cyst $(22.47 \%)$ which is higher than those having only the other two combinations showing that a student with menstrual irregularity is more likely to have a cyst and vice versa. Twenty students $(10 \%)$ had a history of thyroid dysfunction. The clinical features of hyperandrogenism among those who had PCOS were like oily skin (13.5\%), acne (25\%), and increased hair growth $(7 \%)$, male pattern thinning of hair $(9.75 \%)$. The other hyperandrogenic features were not considered in the diagnosis of PCOS as there is no standardized method that uses these features to satisfy the Rotterdam criteria of clinical hyperandrogenism. None of the students gave a self or family history of late onset congenital adrenal hyperplasia or galactorrhoea. This was comparable with studies done on familial PCOS recommended that subjects with classic features of PCOS, anovulation and hyperandrogenism, may have an affected sister who is equally hyperandrogenemic, but has regular cycles and polycystic ovaries. ${ }^{15-17}$

\section{CONCLUSION}

The prevalence seen in this study was $30 \%$ which is on a higher side so the disease should be given more importance by means of early screening and diagnosis. This should be followed up counselling regarding lifestyle modifications. The awareness of the presence of a disease called PCOS among the general public is alarmingly low so it is important to educate the masses about the complications associated and need for prevention.

\section{Funding: No funding sources}

Conflict of interest: None declared

Ethical approval: The study was approved by the Institutional Ethics Committee

\section{REFERENCES}

1. Chen X, Yang D, Mo Y, Li L, Chen Y, Huang Y. Prevalence of polycystic ovary syndrome in unselected women from southern China. Eur J Obstet Gynecol Reprod Biol. 2008;139(1):59-64.

2. Michelmore KF, Balen AH, Dunger DB. Polycystic ovaries and associates; clinical and biochemical features in young women. Clin Endocrinol. 1999;51:779.

3. Asunción M, Calvo RM, San Millán JL, Sancho J, Avila S, Escobar-Morreale HF. A prospective study of the prevalence of the polycystic ovary syndrome in unselected Caucasian women from Spain. J Clin Endocrinol Metab. 2000;85(7):2434-8.

4. Tasali E, Van Cauter E, Ehrmann DA. Relationships between sleep disordered breathing and glucose metabolism in polycystic ovary syndrome. J Clin Endocrinol Metab. 2006;91(1):36-42.

5. Giudice LC. Endometrium in PCOS: Implantation and predisposition to endocrine CA. Best Pract Res Clin Endocrinol Metab. 2006;20(2):235-44.

6. Cerda C, Perez-Ayuso RM, Riquelme A, Soza A, Villaseca P, Sir-Petermann T. Nonalcoholic fatty liver disease in women with polycystic ovary syndrome. J Hepatol. 2007;47(3):412-7.

7. Hollinrake E, Abreu A, Maifeld M, Van Voorhis BJ, Dokras A. Increased risk of depressive disorders in women with polycystic ovary syndrome. Fertil Steril. 2007;87(6):1369-76.

8. List of goals, targets, and indicators. Available at: www.worldbank.org.

9. Kumarapeli V, Seneviratne RD, Wijeyaratne CN. A simple screening approach for assessing community prevalence and phenotype of polycystic ovary syndrome in a semi-urban population in Sri Lanka. Am J Epidemiol. 2008;168:321.

10. Deswal R, Dang AS. Prevalence of poly cystic ovary syndrome (PCOS) in North Indian Women. Indian J Health Well-being. 2014;5(6):742-4. 
11. Rotterdam ESHRE/ASRM-Sponsored PCOS Consensus Workshop Group. Fertil Steril. 2004;81(1):19-25.

12. Norman RJ, Dewailly D, Legro RS, Hickey TE. Polycystic ovary syndrome. Lancet. 2007;370:68597.

13. Esmaeilzadeh S, Delavar MA, Amiri M, Khafri S, Pasha NG. Polycystic ovary syndrome in Iranian adolescents. Int $\mathrm{J}$ Adolesc Med Health. 2014;26(4):559-65.

14. Bindu BR. Increasing incidence of PCOS in adolescence and its relation with mental Stress. Res J Recent Sci. 2014;3(ISC-2013);227-30.

15. Carmina E, Lobo RA. Polycystic ovaries in hirsute women with normal menses. 2001;111(8):602-6.
16. Carey AH, Chan KL, Short F. Evidence for a single gene effect causing polycystic ovaries and male pattern baldness. Clin Endocrinol (Oxf). 1993;38(6):653-8.

17. Legro RS, Driscoll D, Strauss JF, Fox J, Dunaif A. Evidence for a genetic basis for hyperandrogenemia in polycystic ovary syndrome. Proc Natl Acad Sci USA. 1998;95(25):14956-60.

Cite this article as: Jalemu RS, Sabbe K, Jalemu G. A cross sectional study to determine polycystic ovarian disease among students of a tertiary care teaching hospital. Int J Reprod Contracept Obstet Gynecol 2019;8:3614-7. 